\title{
Produção operária italiana e movimento sanitário brasileiro: contribuições para pensar a noção de coletivo
}

\author{
Italian workers production and Brazilian sanitary movement: \\ contributions to think the notion off collective
}

Cristian Guimarães ${ }^{1}$

DOI: $10.1590 / 0103-11042019 S 510$

RESUMO O artigo discute o movimento operário italiano e sua influência na produção do pensamento do movimento sanitário brasileiro, problematizando o modo como a noção de coletivo vai sendo construída no campo da saúde coletiva. Pretende-se compreender como forças marginais contribuíram para a composição do pensamento que animou o movimento sanitário brasileiro nos anos 1970 e 1980. O objetivo foi discutir elementos do contexto italiano da segunda metade do século XX que ajudem a pensar a noção de coletivo no interior do movimento sanitário e da saúde coletiva. Para atingir o objetivo proposto, foi realizado um resgate histórico do pensamento operário italiano. Utiliza-se a história do ponto de vista genealógico, ou seja, para diagnosticar aquilo que somos no presente, pois, desse modo, parece ser possível oferecer novos elementos que ajudem a pensar o movimento sanitário brasileiro na atualidade.

PALAVRAS-CHAVE Política de saúde. Saúde pública. História.

\begin{abstract}
The article discusses the Italian labor movement and its influence in the production of the Brazilian health movement thinking, problematizing the way in which the notion of collective is being built in the field of collective health. It is intended to understand how marginal forces contributed to the composition of the thinking that animated the Brazilian health movement in the 1970's and 1980's. The objective is to discuss elements of the Italian context of the second half of the twentieth century that help to think the notion of collective within the sanitary movement and collective health. In order to achieve the proposed objective, a historical rescue of the Italian labor thought will be carried out. History is used from a genealogical point of view, that is, to diagnose that what we are in the present, because in this way it seems possible to offer new elements that help to think the Brazilian sanitary movement today.
\end{abstract}

KEYWORDS Health policy. Public health. History.

1 Escola de Saúde Pública -

Porto Alegre (RS), Brasil.

crisfabg@gmail.com 


\section{Introdução}

Este manuscrito explora a influência do Movimento Operário Italiano (MOI) na produção do pensamento sanitário brasileiro, problematizando o modo como a noção de coletivo vai sendo construída no campo da saúde coletiva. Desse modo, pretendemos chamar a atenção do leitor para a compreensão de como forças marginais contribuíram para a composição do pensamento que animou o movimento sanitário brasileiro nos anos 1970 e 1980. Lançar um olhar genealógico para essa questão faz aparecer algumas potencialidades capazes de produzir novas formas de compor o movimento sanitário brasileiro na atualidade. Desse modo, o objetivo é trazer à cena elementos do contexto italiano da segunda metade do século XX que ajudem a pensar uma noção de coletivo no interior do movimento sanitário e da saúde coletiva. Revisitar esse cenário de lutas e de disputas pode contribuir para fazer emergir caminhos outros para pensar o movimento sanitário no campo da saúde coletiva.

A invenção da saúde coletiva representou um importante avanço para o pensamento em saúde no Brasil. É consenso que o conhecimento produzido nesse campo tem contribuído significativamente para o avanço do Sistema Único de Saúde (SUS). Historicamente, muitos autores discutiram como a saúde coletiva foi construída ${ }^{1-12}$, situando sua emergência no contexto das agitações reformistas. Tomando como ponto de partida esse registro histórico, parece ser possível afirmar que a saúde coletiva é um campo de conhecimentos e de práticas singular e em constante tensão, cuja consistência, assim como a sua potência em provocar mudanças na realidade, reside na afirmação no plano do conhecimento da pluralidade de vozes reformistas, por meio da expressão do coletivo no campo da saúde. Desse ponto de vista, a problematização do coletivo na saúde coletiva parece sugerir um caminho para repensar o movimento sanitário no contexto atual. Para defender esse argumento, propomos revisitar o pensamento italiano, resgatando o MOI, tomando como eixo o problema do coletivo no campo da saúde.

A importância dessa reflexão para o movimento sanitário reside naquilo que Guimarães ${ }^{13}$ discutiu sobre o problema do coletivo no campo da saúde, constituindo-se como ponto de partida para a reflexão deste manuscrito:

O efeito de uma política que insiste em determinar de antemão um sentido para o coletivo produz a ausência do coletivo na saúde. Efeito paradoxal, uma vez que parece existir um excesso de coletivos na contemporaneidade, cada um expressando bandeiras de lutas importantes, mas particulares. Como pensar um campo de lutas 'coletivo', sem que esse 'coletivo' pareça um amontoado de fragmentos no cenário atual da saúde? Como pensar um campo de lutas coletivo, quando o que está colocado no território da saúde tende à fragmentação das lutas? ${ }^{13}$ (294).

A partir da provocação colocada pelo autor, a questão que anima nossa discussão pode ser assim enunciada: quais provocações o pensamento operário italiano pode oferecer para repensar o coletivo no campo da saúde? Que contribuições podem ser extraídas para que a saúde coletiva se afirme enquanto pensamento potente que expressa a pluralidade de pensamentos e afetos existentes em direção à afirmação de um movimento sanitário na atualidade? Tal pensamento precisa levar em consideração linhas de captura da subjetividade, que se afirmam enquanto vetores de atualização e de produção de sentidos homogêneos. Para construir nossos argumentos, utilizaremos a estratégia genealógica ${ }^{14-16}$ e o recurso da problematização, tendo em vista colocar velhos problemas de forma inventiva e original.

Analisando a literatura sobre o surgimento da saúde coletiva, podemos observar a existência de três direções explicativas, que não estão separadas umas das outras, para a composição desse saber: a abertura, no âmbito acadêmico, para novas leituras da realidade, à luz do discurso das ciências humanas e sociais; a ampliação do 
conceito de saúde e o consequente alargamento do campo sanitário, antes restrito às questões de higiene social ou de adaptação dos indivíduos ao meio ${ }^{17-20}$; e não menos importante, embora de forma mais tímida: as agitações reformistas que animaram a institucionalização do SUS no Brasil, tomando como eixo de discussão a questão do coletivo ${ }^{\mathbf{8}, 9,21-23}$. Da concatenação desses três movimentos no plano do saber, toma corpo a saúde coletiva em sua singularidade.

Ao analisar a noção de coletivo na saúde coletiva, Guimarães e Neves ${ }^{\mathbf{2 1}, 22}$ reencontram o campo problemático das reformas sanitárias, contexto no qual se articulou o movimento sanitário brasileiro, sendo que a problematização desse campo parece ser central para encontrar novos sentidos para pensar o movimento sanitário na saúde coletiva. Portanto, não foram apenas a ampliação do conceito de saúde e/ou a introdução do discurso das ciências humanas e sociais que contribuíram para a construção da saúde coletiva; é preciso considerar nesse cenário os efeitos que a noção de coletivo produz e suas implicações ${ }^{13}$.

Explorar alguns aspectos do movimento produzido na Itália na segunda metade do século $X X$ se justifica, haja vista a influência do pensamento italiano sobre o movimento construído no Brasil a partir dos anos 1970. Utilizando-se da perspectiva genealógica, busca-se entender as práticas de objetivação do conhecimento e das experiências concretas, assim como os processos de subjetivação que operam sobre nosso campo de estudo. Com vista a atingir o objetivo proposto nesse texto, faremos um resgate histórico do pensamento operário italiano. Revisitar a história só tem sentido se ela contribuir para diagnosticar aquilo que nos tornamos na atualidade ${ }^{16}$, pois, desse modo, parece ser possível visualizar novos elementos que ajudam a pensar o movimento sanitário brasileiro na atualidade.

\section{O contexto das lutas/ disputas}

Para entender o campo de disputas e de produção de sentidos das agitações do movimento sanitário no período que tomou força a crítica à saúde pública, é preciso resgatar a influência da experiência italiana no processo brasileiro. Utiliza-se o termo 'agitação' para falar de uma dimensão política que expressa o jogo das lutas operárias no contexto italiano e/ou o processo de redemocratização no cenário brasileiro. Assim, estabelecemos uma relação entre o surgimento da saúde coletiva e as agitações sociais ocorridas na Itália na segunda metade do século XX, uma vez que muitas discussões realizadas no Brasil no período tiveram como referencial ideias cuja origem se situa no contexto italiano ${ }^{24,25}$.

Resgatar a experiência italiana é importante porque, ao discutirmos a história da saúde coletiva no Brasil, parece que passamos rapidamente pela análise da relação entre a reforma sanitária italiana e a brasileira, assim como as implicações dessa relação na composição da saúde coletiva. Guimarães ${ }^{\mathbf{1 3}}$ mostra que não olhar para essa relação histórica dificulta a compreensão dos sentidos atribuídos ao coletivo na saúde. Na Itália, por exemplo, é possível encontrar a produção de um saber operário que impactou decisivamente na composição de um conhecimento singular na saúde. Tal experiência chegou no Brasil a partir de uma perspectiva denominada coletivo-sociedade-civil, embora a perspectiva genealógica tenha apontado outros sentidos em disputa para a noção de coletivo em solo italiano durante as agitações operárias. O coletivo, entendido como sociedade civil organizada, parece ter sido o eixo central do pensamento reformista no contexto brasileiro, embora o movimento sanitário não se constituísse de forma homogênea, havendo tensões dentro do próprio movimento. Essa forma de objetivação do coletivo tornou-se objeto de produção do conhecimento no campo da saúde coletiva, especialmente nos estudos sobre a participação e o controle social no campo da saúde.

Ao analisar a experiência italiana, Guimarães ${ }^{13}$ demonstrou que a noção de coletivo se expressa de formas distintas na saúde, contribuindo para entender a importância desse conceito para a saúde coletiva. Não foi 
apenas o coletivo-sociedade-civil que ocupou lugar de destaque no pensamento existente no período em discussão, valorizando a ideia de que coletivo se confunde com a sociedade civil. O coletivo-população, por exemplo, bastante utilizado pela saúde pública, também sempre esteve presente na saúde coletiva, colocando em ato a ideia de que, ao produzir conhecimento ou intervir sobre a população, estaríamos operando sobre o coletivo. Por fim, destaca-se o coletivo-grupo, que toma forma a partir do discurso oriundo da aproximação das ciências humanas e sociais com a saúde, tomando o grupo como expressão de uma totalidade e a partir de um modo de olhar que aborda a noção de grupo como um indivíduo.

Percebe-se, portanto, que o coletivo no campo da saúde, ao ser objetivado, reproduz formas instituídas no plano do conhecimento; em especial, na saúde coletiva. No entanto, parece ser possível olhar para o coletivo a partir de um outro ponto de vista, recolocando o problema do movimento e da produção, características do movimento sanitário e da sua potência instituinte: o coletivo enquanto potência, que desorganiza as formas instituídas de coletivo. Ora, enquanto forma, o coletivo é representado sob certas condições de equilíbrio que determinam uma política ou uma potência específica na saúde, nada mais que isso. O coletivo-população afirma a segmentação dos sujeitos, sua serialização e hierarquização: organiza-se enquanto discurso do risco, colonizando o futuro no presente, desconecta do sujeito o devir, controlando suas virtualidades. O coletivo-grupo homogeneíza as experiências dos sujeitos em torno de um pensamento de massa, individualizado. Já a crítica que pode ser construída em relação ao coletivo-sociedade-civil aponta que ele se tem mostrado potente no sentido de afirmar interesses privados, fragmentando as lutas em torno de interesses individuais.

Por outro lado, ao entender o coletivo como potência, o que interessa é sua dimensão instituinte, que se expressa como variação contínua que faz escapar a forma, liberando uma dimensão intensiva ${ }^{26}$. O coletivo-potência não se expressa como aquilo que já está constituído pela forma, mas enquanto movimento de produção da crise do constituído ou do formado, abrindo possibilidade para a expressão do devir. Com ele, uma outra política se afirma, diferente daquela que tende a repetir as formas e seu equilíbrio.

No campo problemático instaurado na Itália no período de composição da reforma sanitária italiana, as discussões sobre a saúde operária parecem expressar aquilo que estamos caracterizando como coletivo enquanto expressão da potência, não como plano das formas. Analisar esse contexto parece se aproximar de uma ideia necessária de saúde coletiva que afirma a expressão do coletivo como potência, recolocando em cena as agitações do movimento sanitário no contexto brasileiro. Para destacar a noção de coletivo-potência, buscaremos o conhecimento produzido pelos operários italianos. A aposta é que a processualidade inventiva do coletivo se expressa nesse contexto enquanto ponto nodal para pensar o movimento sanitário brasileiro e a saúde coletiva. Colocar em cena o plano intensivo aberto pelo coletivo no período estudado remete à atualidade dessa noção no campo da saúde coletiva expressando uma dimensão singular para pensar o movimento sanitário no cenário brasileiro na atualidade.

\section{A produção operária no contexto italiano}

Na segunda metade do século XX, configurou-se, na Itália, um movimento singular denominado MOI, inaugurando um campo de lutas políticas que se diferenciava do modelo prescrito pela tradição marxista tradicional, e que produziu efeitos importantes em várias dimensões da realidade. Trata-se de um acontecimento histórico que teve importantes implicações para a saúde no cenário italiano, culminando, em 1978, no Servizio Sanitario Nazionale. Antonio Negri27-30, Mario Tronti31,32, Romano Alquati33,34 e Félix Guattari35,36 ajudaram a pensar essa experiência, 
que se inicia com a assinatura da constituição em 1948, estendendo-se até o final dos anos 1970. Didaticamente, o MOI pode ser dividido em três períodos distintos, que ajudam a situar o contexto do qual deriva um pensamento que vai produzir efeitos sobre o pensamento em saúde no cenário italiano.

O primeiro período pode ser situado a partir da assinatura da constituição italiana em 1948. Esse momento foi importante, porque selou a impossibilidade de a esquerda italiana - ou seja, o partido comunista - chegar ao poder, enquanto jovens proletários, com ideias de revolução social, conduziam lutas armadas com o objetivo de reprimir o fascismo. Nesse período, o esforço dos partidos italianos buscava a articulação de um pacto de vontades em torno da constituição, fortemente condicionado pelos acordos internacionais vigentes naquele momento. Trabalhadores politicamente ativos começam a ser despedidos das fábricas, ao mesmo tempo que o Partido Comunista mediava e representava a tensão existente entre os operários. Esse processo conduziu, nos primeiros anos da década de 1950, à construção de uma forte crítica ao 'partido' como mecanismo de representação dos anseios dos operários: as forças sociais eram contidas pelos partidos políticos que, ao chamar para si a responsabilidade pela luta de classes e assumir uma postura de equilíbrio de vontades, apaziguavam as forças sociais, colocando em ato um equilíbrio social frágil, que produzia efeitos sobre o pensamento dos operários. O efeito mais dramático, segundo $\mathrm{Negri}^{30}$, era dificultar a construção de uma realidade diferente daquela inerente ao modo de produção capitalista.

Para Guattari e Rolnik ${ }^{36}$, nesse período, ganha corpo na Itália um agrupamento operário denominado 'i marginatti', organizado a partir da percepção de um processo geral de marginalização como contraponto àquilo que o pensamento da época propunha:

Toda perspectiva dos capitalistas, e também dos partidos socialistas - clássicos e/ ou marxistas - é acelerar esse processo de entrada nos fluxos capitalísticos, promover o progresso, segundo uma certa concepção. Para eles, é muito importante que esta função de Estado se desenvolva, ou seja, que se incrementem os equipamentos coletivos clássicos [como os partidos e os sindicatos, estimulando a composição de uma sociedade civil organizada]. Quanto aos problemas de mudança da vida cotidiana, da economia do desejo, esses eram deixados de lado, não tinham importância. Mas a história nos mostra que esse corte não é absolutamente pertinente: a concepção da luta social em diferentes etapas desemboca no fato de que a problemática de reconstrução de um tecido social, a problemática da autogestão e da valorização social, é sempre retardada, sempre adiada. O que acontece é que essa função de subjetivação capitalística, esses equipamentos de Estado que se instauram no conjunto do corpo social, se fazem em proveito das novas castas burocráticas, das novas elites que não têm a menor intenção de se despojar do seu poder ${ }^{36(147) .}$

Nos anos 1950, a fase de equilíbrio começou a se romper na Itália, fragilizando a estabilidade que fora construída durante os anos anteriores, marcando a entrada para a segundo período. Com os 'i marginatti', uma ruptura na lógica stalinista no interior do partido comunista tomou forma, e novos sentidos para a realidade foram propostos pelos operários, resultando na composição de uma experiência diferente de luta social. A experiência desse período foi registrada na revista 'Quaderni Rossi' durante os anos de 1956 - 1958, colaborando com a formação de uma base teórica para a consolidação do MOI.

A crítica intelectual do período denunciava a incapacidade de ultrapassar a lógica da representação política, tendo em vista lançar um discurso novo, uma vez que constatava no cenário italiano que o Partido Comunista equacionava as demandas sociais por meio do controle e da representação dos movimentos sociais: o partido filtrava as necessidades sociais que emergiam dos movimentos, absorvendo o conhecimento e utilizando-o como 
instrumento de regulação social no interior dos equipamentos de Estado. Foi com a percepção de que as instituições da sociedade civil - os partidos políticos e os sindicatos - tendiam a responder à demanda de mediação das forças sociais que se organizou o estopim de um processo histórico que produziu mudanças profundas no cenário italiano.

Nesse período, ganha forma a terceira etapa, na qual se concatenou uma experiência singular entre os operários italianos, que se tornou um movimento de construção de um sentido outro de direção para a sociedade, que extrapolou o ambiente restrito da fábrica. Esse momento é importante, porque, a partir da realidade local da fábrica, foram pensadas novas alternativas para a realidade de forma ampla; tal processo moveu a imaginação e o pensamento dos operários em torno de noções que aproximavam a dinâmica existente no interior da fábrica da vida cotidiana, denunciando a reprodução desta como se representasse o circuito da fábrica. Sobre essa base, criaram-se as condições para a constituição do MOI. Momento de renovação do pensamento dos operários, para além da racionalidade produzida pelo modo de produção do trabalho no interior das fábricas, focado na hierarquia, na segmentação e individualização dos operários, e na sua consequente infantilização; agitação intensiva/constituinte que investiu a vida no contexto italiano, ampliando o modo de compreender a realidade.

Os operários entenderam que o modo de racionalizar a vida produzida como discurso de verdade pela ciência oficial sobre o operário, assim como a repetição cotidiana dos processos produtivos de trabalho nas fábricas, dificultava que eles adquirissem a capacidade de organizar/gerir o seu processo de trabalho. Tal discurso de verdade objetivava o trabalhador-operário que, ao consumir esse saber objetivado sobre si mesmo, afastava-se da experiência concreta com o trabalho, assim como da análise da subjetividade que tal engrenagem produzia. Um modo de existência percebido enquanto composição de uma realidade homogênea e destituída de sentido foi problematizado nesse período pelos operários italianos. A produção do conhecimento ou a análise operária do cotidiano era realizada por meio de assembleias nas fábricas, por exemplo, na relação concreta com o trabalho, a partir da experiência concreta dos trabalhadores. Com isso, todo um saber organizado em torno de uma racionalidade alinhada à exploração do trabalho e à reprodução de uma experiência mecanizada em sua relação com a existência era desnaturalizada.

A construção de pensamento que desloca o operário do espaço da fábrica para a percepção mais ampla de que a vida funcionava como se fosse uma grande fábrica desacomodava os operários. Ao se experimentarem como 'peças da engrenagem', o pensamento se movimentava, fazendo o operário-indivíduo-peça-da-engrenagem transbordar. Com ele, todas as expressões do operário como população, grupo ou sociedade civil ruíam. É nesse ponto que o coletivo como potência se expressa enquanto variação, plano de intensidades, processualidade instituinte ${ }^{21,22}$, colocando as condições para a expressão de um sujeito político em devir, ainda não formado e aberto. Com a problematização do coletivo-grupo-operário-representado ou do coletivo-população-a-ser-gerenciada, percebe-se a contaminação/envenenamento que a engrenagem da fábrica produzia, disparando uma variação: o problema já não era mais da ordem da disputa entre individualidades - partidos políticos ou indivíduos -, mas de abertura para a passagem de um coletivo em devir sobre um campo problemático. Dois elementos parecem centrais nessa discussão: o movimento da imaginação dos operários e a produção de novas afecções construídas a partir da modificação dos afetos dos operários.

Para Guattari e Rolnik ${ }^{\mathbf{3 6}}$, os anos que marcaram a emergência do movimento operário foram de intenso movimento desejante, citando-se como exemplo a Rádio Alice em Bolonha, na qual o pensamento operaísta foi difundido e somado às experiências da luta operária e estudantil. Ao olharmos para essa experiência no contexto atual, a questão que 
se coloca diz respeito a como sustentar tal agitação instituinte. Desse modo, o desafio parece estar em como sustentar a variação do coletivo, condição para a produção da diferença, mantendo vivo o movimento da potência. A experiência dos italianos no período estudado mostra ser necessária para desmontar as formas instituídas, desinvestindo-as de sentido. Tal desafio parece similar ao desafio que se coloca na atualidade no contexto brasileiro, quando se pensa o movimento sanitário: como operar no plano das afecções e dos afetos para fazer escapar os mundos individuais fortemente encarnados nos sujeitos em direção à composição de uma luta comum, embora não homogênea? Comum é entendido aqui como devir político contemporâneo, ou seja,

conjunto de práticas que se opõe aos modelos privado e estatal de organização [que está] associado à luta anti-neoliberal, e conectado à ideia de que é preciso reconstruir a democracia37(9).

Acompanhando os desdobramentos do movimento operário é possível visualizar alguns vetores de captura da potência do coletivo, que sugerem alguns desafios para pensar o movimento sanitário no contexto atual.

\section{Vetores de captura ou a produção do instituído no movimento operário italiano}

Os anos 1970, na Itália, foram acompanhados de uma mudança importante no perfil do operariado italiano e mundial, em sintonia com a mutação do modo de produção capitalista, acompanhado pela industrialização e pela mudança dos processos de trabalho. Se, de um lado, os operários se reinventavam no encontro com a problematização/desnaturalização da realidade, de outro, a lógica capitalista agia reconhecendo e integrando os processos criativos e articulando novas formas de dominação. Intensifica-se no interior da fábrica a divisão do trabalho, levando à composição de uma nova força de trabalho. Os operários denunciavam essa organização como uma estratégia capitalística que promovia a perda da força política operária, assim como de sua capacidade de controlar o processo de trabalho. Organizava-se a massificação ou proletarização da classe operária italiana, diagnosticada como mecanismo de domínio capitalista. Pasolini ${ }^{38}$ foi quem melhor expressou esse processo em um texto denominado ' $\mathrm{O}$ vazio do poder' ou 'O artigo dos Vagalumes'.

Essa capacidade do capital de reconhecer a produção inventiva e integrá-la à dinâmica do capital é uma questão importante e nos ajuda a entender os vetores ou linhas de atualização e seu esforço em cristalizar a variação disparada pelo coletivo-potência em formas instituídas. Reconhecer e integrar são dois processos que ajudam a entender como os vetores de subjetivação operam no território da saúde, transformando as agitações em ofertas de produtos a serem consumidos pelos indivíduos de forma alienada e em sintonia com o mercado.

Ora, nesse cenário, o movimento operário enquanto 'classe' toma forma. Seria necessário indagar se, no contexto brasileiro, o movimento sanitário, entendido enquanto expressão da participação social, também não se tenha institucionalizado na 'classe' denominada controle social. Ao se institucionalizar, a potência é estabilizada, já não se expressa como variação. Na Itália, uma noção de 'autonomia operária’ vai ganhando corpo, portanto; seus pressupostos se assentavam nas ideias de autonomia de classe e antiautoritaríssimo. Pelo menos três pensadores criticaram o que estava acontecendo no período: Mario Tronti, que discutia a duplicidade da força de relação entre 'classe operária' e capital, afirmando a capacidade da primeira de produzir, ao mesmo tempo, conservação e resistência ${ }^{31,32}$; Antonio Negri, que elaborou uma releitura do pensamento marxista ${ }^{\mathbf{2 8}, 29}$; e Romano Alquati ${ }^{\mathbf{3 3}, 34}$, que afirmava que a luta de classes não se efetiva de 
fora, mas no interior da 'classe operária', em que se devem construir processos de subjetivação que permitam liberar o desejo.

Agora, o entendimento era o de que a 'classe operária', enquanto representante do 'capital do trabalho', estava submetida ao comando de uma dinâmica que forjava uma figura denominada 'operário capital'. O capital era entendido como relação; ele não comanda se não existe relação. A determinação é sempre dupla e caracterizada pela relação de forças em conflito. O operário, ao explorar subjetivamente a fábrica, experimentava um desejo de comando sobre o trabalho. Já não se trata mais de deixar trabalhar a imaginação dos operários, no que ela tem de instituinte. $O$ que se constituiu nesse período diz respeito a um modo de operar sobre a realidade de forma fiscalista e vigilante. Uma espécie de 'polícia analítica' se institui entre os operários, colocando em evidência um saber que se afirma sobre um traçado similar àquele desenhado pelo capital. O exercício da polícia analítica do operariado produziu saberes globais, que interpretavam e generalizavam as experiências locais. A realidade das experiências locais, múltiplas e singulares, passa a ser determinada por um saber hegemônico e global, despotencializando a possibilidade de construção de um conhecimento regional, com força para produzir e encadear dimensões da realidade que estão aparentemente desligadas umas das outras. A polícia analítica constitui-se, portanto, como elemento importante para entender o processo que conduziu à determinação do movimento operário, caracterizado pela captura da capacidade inventiva, ou seja, como instituição de uma polícia que se instaurou como sistema de controle da imaginação e produção de sentido sobre a figura do operário.

O reconhecimento de que os operários italianos, cada vez mais, consolidavam-se enquanto 'classe' com capacidade de produzir mudanças, bem como de dinamizar o movimento operário e estabelecer relações materiais e de renovação contínua sobre a realidade concreta, ganha força. O processo se institui enquanto 'tomada de consciência' da própria força: é a 'classe operária' constituída como consciência de classe, agenciada sob a forma de polícia analítica que ganha espaço nesse momento.

Ao mesmo tempo que se concatena esse 'novo operário', um intenso processo de repressão ganha força no cenário italiano. Os documentos escritos pelos operários na época denunciavam a utilização capitalista da crise aberta pelos operários, ou seja, a produção de um discurso que culpabiliza o operariado pela crise vivida na Itália no período das lutas operárias, que se agencia em torno da violência e do combate ao terrorismo. Simultaneamente, tais documentos ofereciam uma solução para que o movimento operário avançasse, qual seja, a homogeneidade do movimento, entendendo como linha de fuga a própria captura: o jogo da unidade, da totalização e do fechamento em um registro individuado/identitário ganha força. O bloqueio da força de variar do coletivo fica evidente, sua potência é instituída, enquanto organismo estável e burocrático de luta. Essa formação (forma de expressão) é aquela que vai animar o ideário reformista dos anos 1970 na Itália. Ora, foi a composição de um coletivo sociedade-civil, caracterizado como 'classe operária', que animou o pensamento de Berlinguer ${ }^{\mathbf{2 4}, 25}$, por exemplo, influenciando a construção da reforma sanitária italiana e chegando ao Brasil nos anos 1970.

Quando, nos primórdios da década de 1970, inicia-se a construção de um compromisso restaurativo que aponta no sentido de estabelecer acordos com a elite do capitalismo mundial, na qual a moeda deveria ocupar o centro do controle das relações sociais, a Itália ainda estava vivendo o processo instaurado pelo movimento operário, ao mesmo tempo que ganhava corpo a expressão de um coletivo instituído enquanto imagem ou forma. Esse momento pode ser compreendido como o início da 'reação capitalista', com a introdução da perspectiva neoliberal. O marcador histórico desse período é o documento 'The Crisis of Democracy: report on the governability of democracies to the Trilateral Comission'39, que expressa os 
acordos obtidos em 1973, quando se constrói o entendimento de que é necessário conter as experiências de participação nos processos de tomada de decisão política existentes, caracterizando um momento histórico importante que impulsionou a visão conservadora calcada na reflexão capitalista que afirmava a necessidade de limitar a democracia.

\section{Processualidades instituintes: movimentos do coletivo como potência na saúde}

Na passagem histórica discutida acima, que durou aproximadamente 20 anos, constituíram-se as bases para pensar a 'saúde operária'. A saúde operária italiana pode ser entendida como uma ideia que expressa em devir a saúde coletiva brasileira. Dito de outra forma: nas discussões sobre a saúde no período, podemos encontrar elementos importantes para entender a genealogia da saúde coletiva. Isso não quer dizer que ela tenha sido inventada pelos italianos, pois é no Brasil que vemos ganhar consistência esse campo de conhecimentos e de práticas. No entanto, encontrar a genealogia do coletivo na experiência italiana permite compreender potenciais linhas de fuga para pensar o coletivo no movimento sanitário brasileiro no campo da saúde coletiva. Será esse o nosso desafio a partir de agora.

Foi a partir dos anos 1960 que os operários italianos perceberam a necessidade de reivindicar constitucionalmente direitos sociais. Nesse período, foram produzidos textos relacionados com a saúde, com o intuito de discutir a questão sob a ótica do movimento operário 40-45. Estavam em jogo a construção da saúde como direito e a reforma sanitária italiana. Berlinguer ${ }^{24,25}$, por exemplo, afirmava que, para a concretização da reforma sanitária na Itália, era necessário abrir espaço à sociedade civil organizada. $\mathrm{O}$ autor discutia o processo da reforma italiana, enfatizando a construção de uma consciência sanitária, que ativaria o processo reformador que culminou na instituição do Servizio Sanitario Nazionale em 1978. Consciência sanitária foi entendida como o processo de tomada de consciência de que a saúde é um direito do indivíduo e interesse da sociedade, sendo que seu desenvolvimento dependia de uma ação coletiva, com intervenção de forças sindicais e políticas ${ }^{24,25}$. Os sindicatos e os partidos políticos deveriam organizar a consciência sanitária, educando a sociedade para a construção de uma nova cultura sobre a saúde.

Para Montuschi ${ }^{46}$, a subversão cultural que caracteriza o processo de tomada de consciência dos trabalhadores se materializou enquanto construção de estratégias de prevenção à saúde do trabalhador nos ambientes de trabalho, tendo como efeito a marginalização do pensamento revolucionário sobre a saúde operária, encontrados em Maccacaro ${ }^{39,41-44}$ e Basaglia ${ }^{45}$. A ação sanitária deveria se entrelaçar com a política, mediante a construção de uma força social e democrática que permitisse o movimento de passagem da produção do saber para a dimensão do fazer concreto. Às instituições da sociedade civil, tais como os sindicatos e os partidos políticos, caberia a passagem para o concreto, ou seja, a produção da consciência sanitária, sem a qual não seria possível uma reforma de largo alcance. Conforme Berlinguer25(7-8), "a saúde, como fenômeno coletivo, requer uma intervenção política, levando-se, sobretudo, em consideração a biologia e a história", uma vez que a maioria dos problemas de saúde estava relacionada com as condições de miséria da população operária.

A valorização do papel das instituições democráticas da sociedade civil se concretiza em um cenário em que o fascismo ainda produzia efeitos, senão concretamente, ao menos na mente das pessoas, pois era lembrado como política de esvaziamento dos canais democráticos de participação por exemplo. Para Berlinguer25(14-15):

É com a criação de organismos que excluíram qualquer participação ativa, qualquer formação de autoconsciência, que a Itália foi levada [...] para os mais atrasados níveis sanitários 
e educativos [...]. O fascismo constata a escassa participação do povo na tutela da saúde [...], observa-se um menor interesse da opinião pública que, inevitavelmente, projeta-se nas instituições e organismos, responsáveis pela defesa sanitária da população.

Os sindicatos e os partidos políticos, pressionados pelos operários operárias, perceberam a oportunidade de discutir a saúde e ocupar um espaço vazio na defesa dos interesses sanitários da população. Tal movimento se concretizou, ao mesmo tempo, em que o movimento operário problematizava a sua realidade. Ao investirem no discurso da tomada de consciência sobre as condições de trabalho operárias, sindicatos e partidos políticos, incomodados com a perda de espaço e de representação, começaram a se mobilizar para assumir aquilo que se entendia como seu papel na educação sanitária dos cidadãos, lançando-se na luta pelas questões sanitárias.

O período foi de intensa disputa pela construção da consciência sanitária dos italianos, uma mistura de crítica produzida pelos operários em movimento e de apropriação por parte dos sindicatos e dos partidos políticos desse conhecimento, tendo em vista fortalecer seu papel enquanto entidades democráticas, contribuindo, dessa forma, para a educação da sociedade. Nesse território de disputas, construiu-se o processo de reforma sanitária naquele país, com forte expressão da polícia analítica sobre a elaboração de um pensamento em saúde dos operários. Para Berlinguer ${ }^{\mathbf{2 4 , 2 5}}$, foi com a participação das instituições da sociedade civil que a reforma italiana ganhou consistência, concretizando-se na lei do Servizio Sanitario Nazionale no final dos anos 1970. O discurso da prevenção foi importante para a composição do modelo médico-sanitário que seria adotado.

Essa linha de pensamento presente na reforma sanitária italiana foi amplamente discutida pelos reformistas brasileiros, como afirmado anteriormente. Na segunda metade da década de 1970, o pensamento de Berlinguer ${ }^{\mathbf{2 4}, 25}$ foi difundido no Brasil, contribuindo para a construção da reforma sanitária brasileira, resgatando a saúde como direito, a democracia e a participação direta da sociedade na construção das propostas que culminaram na constituição de 1988.

Guattari $^{35}$ ajuda a problematizar a forma como Berlinguer interpretou/traduziu o processo italiano, expressando o paradoxo existente nessa linha de pensamento. $\mathrm{O}$ autor afirma que o MOI corrompeu a crença na valorização da sociedade civil organizada em sindicatos ou partidos. O movimento operário produziu uma crise que deslocou a ideia de operário e de movimento como formas homogêneas, assim como a expressão da vontade operária nos partidos políticos ou nas instituições da sociedade civil. Percebe-se, portanto, que se produziram na Itália movimentos em diferentes níveis e com distintas formulações; de modo que resgatar outros autores que problematizaram o processo ocorrido na Itália de forma diferente de Berlinguer ${ }^{\mathbf{2 4}, 25}$ pode fornecer pistas para pensar o movimento sanitário brasileiro na atualidade, a exemplo de Maccacaro ${ }^{40-44}$, pois, nesse autor, encontramos uma via original para pensar a saúde e o coletivo.

\section{Reflexões finais}

A análise genealógica da saúde coletiva sugere haver uma relação entre a formulação de uma noção de coletivo no campo da saúde no encontro com as lutas e disputas produzidas na Itália na segunda metade do século XX e o movimento sanitário brasileiro. A problematização dessa relação histórica fez emergir alguns elementos que parecem importantes para pensar o movimento sanitário brasileiro, bem como a produção de saberes e de práticas sobre esse tema no campo da saúde coletiva.

Procurou-se evidenciar que o movimento sanitário brasileiro se configurou a partir dos anos 1970, tomando como eixo de análise o MOI e o problema do coletivo no campo da saúde. Inicialmente, convidou-se o leitor para refletir 
sobre as formas de expressão do coletivo no campo da saúde. Em seguida, foi discutido o pensamento do MOI, a fim de resgatar suas potencialidades, as formas de captura e as linhas de fuga que são pistas para pensar o movimento sanitário e a saúde coletiva no contexto brasileiro.

Se a experiência do MOI pode, hoje, tocar a saúde coletiva, tensionando a variação do coletivo e criando as condições de possibilidade para a emergência de novos discursos no interior desse campo de conhecimentos e de práticas, parece ser possível que um movimento radicalmente novo possa se afirmar e ganhar consistência. Sustentar a variação disparada pelo coletivo na saúde pode abrir espaço para a experimentação de novos devires, combustível para produzir agitação no pensamento sanitário brasileiro que contribua para a (des)organização do movimento sanitário. Se algo pode colaborar para o movimento sanitário, esse algo parece ser o desafio de sustentar a variação do coletivo, para que a potência de variar expresse sua força. Quando a saúde coletiva é tocada pelo coletivo enquanto plano intensivo e processualidade instituinte, ela é forçada a experimentar novas afecções, e um novo corpo teórico e prático pode ganhar consistência e animar o movimento sanitário brasileiro.

A análise das contribuições do MOI sugere não ser possível disparar a variação do coletivo sem prestar atenção à potência da imaginação de outras formas de luta possíveis e de produção de coletivo. Problematizar a imaginação coloca em evidência o quanto ela é domesticada, ou seja, faz aparecer as políticas de subjetivação que operam delimitando muito bem aquilo que pode ser imaginado, procedimento que esvazia a potência de variar. Tal reflexão é importante porque já não parece ser possível partir da ideia de compor o coletivo empilhando indivíduos com interesses privados e discordantes, em um projeto que se expresse enquanto totalidade ou forma homogênea. Resta pensar quais elementos teóricos e práticos podem provocar a saúde coletiva a se mover do plano representacional do coletivo, ou seja, da sua forma instituída, que reproduz cópias de coletivo, para a produção de coletivos que disparam a variação enquanto expressão da potência.

Não parece haver dúvida de que o coletivo é uma aposta consistente para afirmar o movimento sanitário brasileiro na atualidade. Assumir essa perspectiva significa operar da forma como os operários italianos fizeram na composição do movimento operário: desnaturalizar as formas instituídas de coletivo, descolonizar o pensamento, tensionar uma variação naquilo que é dado ou possível de ser imaginado, que tende a reduzir a compreensão do mundo e das coisas, abrindo passagem para novos encontros e composições singulares. Ao mesmo tempo, conhecer a história do MOI e atentar às capturas que esse movimento experimentou ajuda a desviar de algumas armadilhas e imaginar outros caminhos possíveis para pensarmos o movimento sanitário brasileiro.

Assim, antes de instaurar um pensamento no campo da saúde coletiva que se afirme como uma polícia analítica, que opera na lógica da homogeneização da imaginação e dos afetos, apostamos na potência inventiva da imaginação e na concatenação de diferentes afetos, a fim de produzir saltos intensivos no pensamento, afirmando a ética da variação, que parece produzir efeitos políticos importantes. Ao invés de sustentar identidades, a ética da variação valoriza aquilo que temos de diferente que compõe um comum $^{26}$. Talvez seja essa uma direção possível para pensar o movimento sanitário na atualidade, não como bloco homogêneo ou como ativador de uma consciência sanitária hegemônica, mas como dispositivo que agencia diferenças sob um traçado comum e transversal às diferentes lutas existentes, que afirma a saúde como problema comum e da ordem da multiplicidade.

\section{Colaborador}

Guimarães C (0000-0003-3101-634X)* contribuiu para a concepção, o planejamento, a análise e a interpretação dos dados; revisão crítica do conteúdo; e aprovação da versão final do manuscrito.
*Orcid (Open Researcher and Contributor ID). 


\section{Referências}

1. Lima NT, Santana JP. Saúde coletiva como compromisso: a trajetória da ABRASCO. Rio de Janeiro: Fiocruz/ABRASCO; 2006.

2. Campos GWS. Como reinventar a gestão e o funcionamento dos sistemas públicos e organizações estatais? Ciênc. Saúde Colet. 2000; 13(sup2):2019-2028.

3. Nunes ED. A sociologia da saúde nos Estados Unidos, Grã-Bretanha e França. Saúde Soc. 2003; 8(1):9-95.

4. Costa NR. Ciências sociais e saúde: considerações sobre o nascimento do campo da saúde coletiva no Brasil. Saúde debate. 1992; 36:58-65.

5. Campos GWS. A saúde pública e a defesa da vida. São Paulo: HUCITEC; 1991. 175 p.

6. Paim JS, Almeida Filho N. Saúde coletiva: uma "nova saúde pública" ou campo aberto a novos paradigmas? Rev Saúde Pública. 1998; 32(4):299-316.

7. Cohn A. Conhecimento e prática em saúde coletiva: o desafio permanente. Saúde Soc.1992; 1(2):97-109.

8. Felipe JS. Uma avaliação da produção teórico-científica da medicina social no Brasil. Saúde debate. 1989; 27:59-66.

9. Merhy EE. O capitalismo e a saúde pública. 2. ed. São Paulo: Papirus; 1987.

10. Fleury S. O dilema reformista na reforma sanitária brasileira. Rev adm Pública. 1987; 21(4):94-115.

11. Teixeira SMF. As ciências sociais em saúde no Brasil. In: Nunes, ED, organizador. As ciências sociais em saúde na América Latina - Tendências e Perspectivas. Brasília: OPAS; 1985. p. 87-109.

12. Luz MT. Notas sobre a política de saúde no Brasil de "transição democrática" - anos 80. Saúde debate. $1991 ; 32: 27-32$.
13. Guimarães CF. O Coletivo na Saúde. Porto Alegre: Rede Unida; 2016.

14. Foucault M. Nietzsche, a genealogia, a história. In: Foucault M. Ditos \& Escritos II: arqueologia das ciências e história dos sistemas de pensamento. Rio de Janeiro: Forense Universitária; 2005. p. 260-281.

15. Foucault M. Sobre as maneiras de escrever a história. In: Foucault, M. Ditos \& Escritos II: arqueologia das ciências e história dos sistemas de pensamento. Rio de Janeiro: Forense Universitária; 2005. p. 62-77.

16. Dreyfus HL, Rabinow P. Michel Foucault, uma trajetória filosófica: para além do estruturalismo e da hermenêutica. 2. ed. Rio de Janeiro: Forense Universitária; 2010.

17. Laurell AC. A saúde-doença como processo social. In: Nune S, Everardo D. Medicina social: aspectos históricos e teóricos. São Paulo: Global; 1983. p.133-158.

18. Birman J. A Physis da Saúde Coletiva. Physis (Rio J.). 2005; 15(supl):11-16.

19. Birman J. Os sentidos da saúde. Physis (Rio J.). 1999; 9(1):7-12.

20. Almeida-Filho N, Paim JS. La crisis de la salud pública y el movimento de la salud colectiva em Latinoamérica. Cuad méd soc (Ros.). 1999; 75: 5-30.

21. Guimarães CF, Silva RAN. Devires e Intensidades do Coletivo na Saúde Coletiva. Physis. 2016; 26(3):939959.

22. Guimarães CF, Silva RAN. Notas para a problematização do coletivo no campo da saúde. Ciênc. Saúde Colet. 2015; 20(3):913-924.

23. Pereira JCM. A explicação sociológica na medicina social [tese]. Ribeirão Preto: Universidade de São Paulo, Faculdade de Medicina; 1983. 
24. Berlinguer G. Medicina e política. 3. ed. São Paulo: Hucitec; 1987.

25. Berlinguer G. Uma reforma para a saúde. In: Berlinguer G, Teixeira SF, Campos GWS. Reforma Sanitária: Itália e Brasil. São Paulo: Hucitec; 1988. p. 1-106.

26. Martin, J-C. Variations: the philosophy of Gilles Deleuze. Edinburgh: Edinburgh University Press; 2010.

27. Negri A. Stato e politica. Milano: Feltrinelli; 1970.

28. Negri A. Proletari e stato: per una discussione su autonomia operaia e compromesso storico. Milano: Feltrinelli; 1976.

29. Negri A. La fabbrica della strategia: 33 lezioni su Lenin. Padova: Cooperativa libraria editrice degli studenti di Padova; 1977.

30. Negri A. La forma Stato: per la critica dell'economia politica della Costituzione. Milano: Feltrinelli; 1977.

31. Tronti M. Operai e capitale. Turim: Einaudi; 1966.

32. Tronti M. Sull'autonomia del politico. Milão: Feltrinelli; 1977.

33. Alquati R. Sindacato e partito: antología di interventi di sindacalisti sul rapporto de sindacato e sistema politico in Italia. Turim: Stampatori; 1977.

34. Alquati R. Lavoro e attività: per una analisi della schiavitù neomoderna. Roma: Manifesto; 1977.

35. Guattari F. Revolução molecular: pulsações políticas do desejo. 3.ed. São Paulo: Brasiliense; 1987.

36. Guattari F, Rolnik S. Micropolitica: cartografias do desejo. 7. ed. Petrópolis: Vozes; 2005.

37. Silveira AS, Savazoni R. O conceito do comum: apontamentos introdutórios. In: Liinc em Revista. 2018; 14(1):5-18.
38. Pasolini PP. Il vuoto del potere "ovvero" l'articolo delle lucciole in: Pasolini PP. Scritti corsari. Gli interventi più discussi di un testimone provocatório. Milano: Garzanti; 1975

39. Crozier MJ, Huntington SP, Watanuki J. The Crisis of Democracy: report on the governability of democracies to the Trilateral Comission. United States of America. Nova York: New York University Press; 1975.

40. Maccacaro GA. Classe e salute. In: Maccacaro GA. Medicina e Potere: per una medicina da rinnovare. Scritti 1966-1976. Milano: Giangiacomo Feltrinelli Editore; 1979.

41. Maccacaro GA. L'unità sanitaria locale come sistema. In: Maccacaro GA. Medicina e Potere: per una medicina da rinovare. Scritti 1966-1976. Milano: Feltrinelli Editore; 1979.

42. Maccacaro GA. L'uso di classe della medicina. In: Maccacaro GA. Medicina e Potere: per una medicina da rinnovare. Scritti 1966-1976. Milano: Giangiacomo Feltrinelli Editore; 1979.

43. Maccacaro GA. Medicina Democratica, movimento di lotta per la salute. In: Maccacaro GA. Medicina e Potere: per una medicina da rinnovare. Scritti 19661976. Milano: Giangiacomo Feltrinelli Editore; 1979.

44. Maccacaro GA. Prática médica e controle social. In: Maccacaro GA. Medicina e Potere: per una medicina da rinnovare. Scritti 1966-1976. Milano: Giangiacomo Feltrinelli Editore; 1979.

45. Basaglia F. A instituição negada. 3. ed. Rio de Janeiro: Graal; 2001

46. Montuschi L. Diritto ala salute e organizzazione del lavoro. Milano: Franco Angeli; 1976.

Recebido em 12/06/2019

Aprovado em 31/10/2019

Conflito de interesses: inexistente

Suporte financeiro: não houve 